\title{
PELABELAN PRIME CORDIAL PADA GRAF MIDDLE
}

\author{
Apistino, Yundari, Helmi
}

\section{INTISARI}

Pelabelan graf adalah pemetaan yang memasangkan unsur-unsur graf dengan suatu himpunan bilangan. Bilangan-bilangan tersebut disebut label. Ada banyak jenis pelabelan graf yang telah dikembangkan dan salah satunya adalah pelabelan prime cordial. Pelabelan prime cordial dari suatu graf $G$ dengan himpunan simpul $V(G)$ adalah fungsi bijektif $f: V(G) \rightarrow\{1,2,3, \ldots,|V(G)|\}$, dengan $|V(G)|$ adalah orde dari graf $G$. Kemudian $f$ menginduksi fungsi $f^{*}: E(G) \rightarrow\{0,1\}$ yang didefinisikan dengan $f^{*}(e=u v)=$ 1 jika $\operatorname{FPB}(f(u), f(v))=1$ dan $f^{*}(e=u v)=0$ untuk yang lainnya dan memenuhi kondisi $\mid e_{f}(0)-$ $e_{f}(1) \mid \leq 1$, dengan $e_{f}(i)$ adalah banyak sisi pada graf $G$ yang berlabel $i$ pada fungsi $f^{*}$, untuk $i=0,1$. Graf yang memuat pelabelan prime cordial disebut graf prime cordial. Salah satu graf terkait yang dikaji dalam pelabelan prime cordial adalah graf middle dari beberapa graf. Graf middle adalah graf yang diperoleh dari graf $G$ dan dinotasikan dengan $M(G)$ dengan $V(M(G))=V(G) \cup E(G)$. Dua simpul bertetangga di $M(G)$ jika dan hanya jika keduanya adalah sisi yang bertetangga dari $G$ atau satu simpul dari $G$ dan yang lainnya bersisian dengan sisinya. Adapun graf yang dibahas dalam penelitian ini adalah graf cycle $\left(C_{n}\right)$, path union dengan dua salinan graf cycle (path union $\left.C_{m}(2)\right)$, dan graf pan $\left(T_{n, 1}\right)$. Hasil penelitian menunjukkan bahwa graf middle pada graf cycle $\left(M\left(C_{n}\right)\right)$ untuk $n=3$ dan $n \geq 5$, graf middle pada path union dengan dua salinan graf cycle (M(path union $\left.\left.C_{m}(2)\right)\right)$ untuk $m \geq 3$, dan graf middle pada graf pan $\left(M\left(T_{n, 1}\right)\right)$ untuk $n \geq 3, n, m \in Z^{+}$merupakan graf prime cordial.

Kata Kunci: Graf Cycle, Path Union, Graf Pan

\section{PENDAHULUAN}

Teori graf pertama kali diperkenalkan oleh Leonhard Euler yaitu seorang matematikawan berkebangsaan Swiss pada tahun 1736 melalui tulisan Euler yang berisi tentang upaya pemecahan masalah jembatan Konigsberg yang sangat terkenal di Eropa. Banyak topik-topik yang dipelajari dari teori graf, salah satunya adalah mengenai pelabelan dari suatu graf. Pelabelan graf adalah pemetaan dari himpunan simpul $(V(G))$ dan/atau himpunan sisi $(E(G))$ ke suatu himpunan bilangan. Bilanganbilangan tersebut disebut label. Jika yang diberi label hanya simpul saja, maka pelabelannya disebut pelabelan simpul. Jika yang diberi label hanya sisi saja, maka pelabelannya disebut pelabelan sisi. Sedangkan jika keduanya, simpul dan sisi diberi label, maka pelabelannya disebut pelabelan total [1].

Penerapan pelabelan graf banyak digunakan pada teori pengkodean kriptografi, radar, astronomi, desain sirkuit, pengalamatan jaringan komunikasi, kristalografi, $x$-ray, dan manajemen basis data [2]. Ada banyak jenis pelabelan graf yang telah dikembangkan diantaranya adalah pelabelan prime cordial. Pelabelan prime cordial dari suatu graf $G$ adalah suatu pemetaan bijektif $f: V(G) \rightarrow\{1,2,3, \ldots, p\}$, dengan $p$ adalah banyaknya simpul pada graf $G$ dan $f$ menginduksi $f^{*}(e=u v)=1$ jika $F P B(f(u), f(v))=1$ dan $f^{*}(e=u v)=0$ untuk yang lainnya, dan memenuhi $\left|e_{f}(0)-e_{f}(1)\right| \leq 1$. Konsep pelabelan prime cordial pertama kali diperkenalkan oleh Sundaram, Ponraj, dan Somasundram pada tahun 2005 [3].

Penelitian selanjutnya yakni mengkaji beberapa pengembangan graf yaitu graf split, graf square dan graf middle dari beberapa graf yang dikonstruksi menjadi graf prime cordial [4]. Pada penelitian ini terfokus pada graf middle. Graf middle adalah graf yang diperoleh dari graf $G$ dan dinotasikan dengan $V(M(G))=V(G) \cup E(G)$. Dua simpul bertetangga di $M(G)$ jika dan hanya jika keduanya 
adalah sisi yang bertetangga dari $G$ atau satu simpul dari $G$ dan yang lainnya bersisian dengan sisinya [5]. Penelitian Vaidya dan Shah hanya mengkaji graf middle dari graf path. Berdasarkan permasalahan tersebut, yang diteliti pada penelitian ini adalah pelabelan prime cordial pada graf middle selain graf path. Penelitian ini mengambil beberapa sampel graf yaitu graf cycle, path union dari graf cycle, dan graf pan, kemudian dikonstruksi menjadi suatu graf middle dan dilanjutkan menjadi graf prime cordial. Pada penelitian ini, label-label yang digunakan dalam fungsi $f$ dan $f^{*}$ adalah himpunan bilangan bulat positif.

\section{TEORI GRAF}

Sebelum membahas pelabelan prime cordial pada graf middle, terlebih dahulu diberikan definisi graf, orde, ukuran, adjacent (bertetangga), dan incident (bersisian), yang dijadikan sebagai dasar untuk pembahasan selanjutnya.

Definisi 1 [6] Graf $G$ didefinisikan sebagai pasangan himpunan $(V, E)$, ditulis dengan notasi $G=(V, E)$, yang dalam hal ini $V$ adalah himpunan tidak kosong dari simpul-simpul dan $E$ adalah himpunan sisi-sisi yang menghubungkan sepasang simpul.

Berdasarkan Definisi 1, diberikan contoh graf $G$ sebagai berikut.

Contoh 2 Diberikan sebuah graf $G$ dengan $V(G)=\left\{v_{1}, v_{2}, v_{3}, v_{4}, v_{5}\right\}$ dan $E(G)=\left\{e_{1}, e_{2}, e_{3}, e_{4}\right.$, $\left.e_{5}, e_{6}\right\}$ dengan $e_{1}=v_{1} v_{2}, e_{2}=v_{2} v_{3}, e_{3}=v_{3} v_{4}, e_{4}=v_{4} v_{5}, e_{5}=v_{1} v_{4}$, dan $e_{6}=v_{3} v_{5}$, sehingga diperoleh graf $G$ dengan 5 simpul dan 6 sisi yang dapat dilihat pada Gambar 1 .

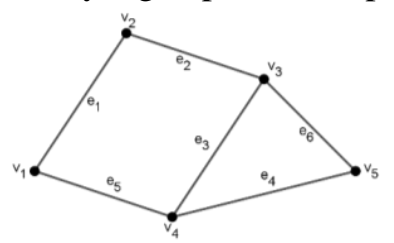

\section{Gambar 1 Graf $G$ dengan 5 Simpul dan 6 Sisi}

Pembahasan selanjutnya adalah mengenai orde, ukuran, adjacent, incident yang dituangkan dalam Definisi 3 dan Definisi 4 sebagai berikut.

Definisi 3 [7] Misalkan diberikan graf G. Banyaknya simpul pada graf G disebut orde dan banyaknya sisi pada graf $G$ disebut ukuran. Orde dari graf $G$ dinotasikan dengan $|V(G)|$ dan ukuran dari graf $G$ dinotasikan dengan $|E(G)|$.

Berdasarkan Gambar 1, diperoleh $|V(G)|=5$ dan $|E(G)|=6$.

Definisi 4 [8] Sisi e =uv dikatakan menghubungkan simpul u dan v. Jika e = uv adalah sisi di graf $G$, maka $u$ dan $v$ disebut terhubung langsung (adjacent), $u$ dan $e$ serta $v$ dan e disebut terkait langsung (incident).

Berdasarkan Gambar 1, misal diambil sebarang simpul yaitu $v_{1}$ dan $v_{2}$ dan diambil sebarang sisi yaitu $e_{1}$. Diperoleh bahwa $v_{1}$ dan $v_{2}$ disebut adjacent, sedangkan $e_{1}$ dan $v_{1}$ serta $e_{1}$ dan $v_{2}$ disebut incident.

\section{PENGKONSTRUKSIAN GRAF MIDDLE PADA BEBERAPA GRAF}

Sebelum membahas pengkontruksian graf middle dari beberapa graf, terlebih dahulu diberikan definisi graf middle sebagai berikut.

Definisi 5 [5] Graf middle pada graf $G$ yang dinotasikan dengan $M(G)$ adalah graf yang himpunan simpulnya adalah $V(M(G))=V(G) \cup E(G)$. Dua simpul adjacent jika dan hanya jika: 
1. $e_{a} \in V(M(G))$ adjacent dengan $e_{b} \in V(M(G))$ karena sisi $e_{a}=v_{i} v_{j} \in E(G)$ dan sisi $e_{b}=$ $v_{j} v_{k} \in E(G)$ incident pada simpul yang sama di graf $G$,

2. $v_{i} \in V(M(G))$ adjacent dengan $e_{a} \in V(M(G))$ karena sisi $e_{a}=v_{i} v_{j} \in E(G)$ incident dengan simpul $v_{i} \in V(G)$.

Graf middle merupakan graf yang diperoleh dari suatu graf dasar dengan syarat tertentu. Adapun graf dasar yang dibahas dalam penelitian ini adalah graf cycle, path union dari graf cycle, dan graf pan. Graf cycle adalah graf sederhana yang setiap simpulnya berderajat dua. Graf cycle dengan $n$ simpul dinotasikan dengan $C_{n}$. Jika simpul pada $C_{n}$ adalah $v_{1}, v_{2}, \ldots, v_{n}$ maka sisi-sisinya adalah $\left(v_{1} v_{2}\right)$ $,\left(v_{2} v_{3}\right), \ldots,\left(v_{n-1} v_{n}\right),\left(v_{n} v_{1}\right)$. Dengan kata lain, ada sisi dari simpul terakhir $v_{n}$ ke simpul pertama $v_{1}[6]$. Selanjutnya, path union adalah graf yang diperoleh dengan menambah sisi diantara $G_{i}$ ke $G_{i+1}$ untuk $i=1,2, \ldots, n-1$ dengan $G_{1}, G_{2}, \ldots, G_{n}, n \geq 2$ untuk $n$ Salinan graf [9]. Pada penelitian ini membahas path union dari 2 salinan graf cycle. Kemudian graf pan adalah adalah graf yang diperoleh dengan menggabungkan graf $C_{n}$ dengan graf tunggal $K_{1}$ dengan sebuah penghubung [10]. Graf pan dinotasikan dengan $T_{n, 1}$. Berikut diberikan ilustrasi dari ketiga graf yang dibahas.

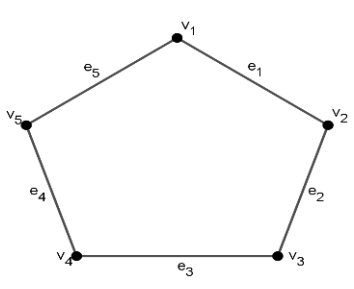

(a)

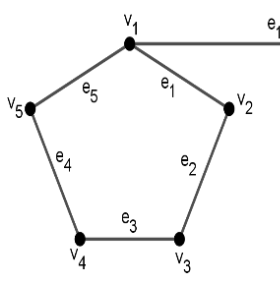

(b)

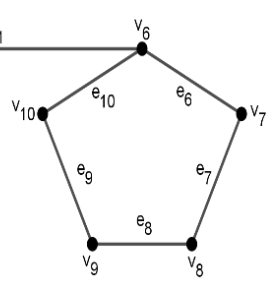

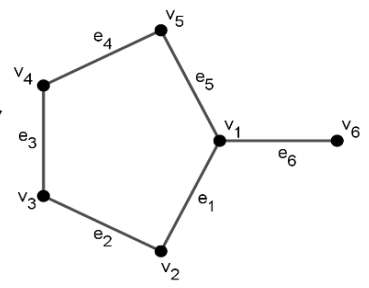

(c)

Gambar 2 (a) Graf $C_{5}$, (b) Path union $C_{5}(2)$, (c) Graf $T_{5,1}$

Berdasarkan Gambar 2, ke tiga graf tersebut dapat dikonstruksi menjadi graf $M\left(C_{n}\right)$, $M\left(\right.$ path union $\left.C_{5}(2)\right)$, dan $M\left(T_{n, 1}\right)$. Untuk graf $M\left(C_{n}\right)$, diberikan himpunan simpul $V\left(C_{n}\right)=$ $\left\{v_{1}, v_{2}, v_{3}, v_{4}, \ldots, v_{n}\right\}$ dan himpunan sisi $E\left(C_{n}\right)=\left\{e_{1}, e_{2}, e_{3}, \ldots, e_{n}\right\}$ sehingga $V\left(M\left(C_{n}\right)\right)=\left\{v_{1}, v_{2}\right.$, $\left.v_{3}, v_{4}, \ldots, v_{n}, e_{1}, e_{2}, e_{3}, \ldots, e_{n}\right\}$. Dua simpul adalah adjacent di $M\left(C_{n}\right)$ dapat dilihat pada Tabel 1 dan Tabel 2 sebagai berikut.

Tabel 1 Pengkonstruksian Graf $M\left(C_{n}\right)$ dengan Syarat Keduanya adalah Sisi yang Bertetangga

\begin{tabular}{|c|c|c|c|c|c|c|c|c|}
\hline & $e_{1}$ & $e_{2}$ & $e_{3}$ & $e_{4}$ & $e_{5}$ & $\ldots$ & $e_{n-1}$ & $e_{n}$ \\
\hline$e_{1}$ & - & $e_{1} e_{2}$ & - & - & - & $\ldots$ & - & $e_{1} e_{n}$ \\
\hline$e_{2}$ & - & - & $e_{2} e_{3}$ & - & - & $\ldots$ & - & - \\
\hline$e_{3}$ & - & - & - & $e_{3} e_{4}$ & - & $\ldots$ & - & - \\
\hline$e_{4}$ & - & - & - & - & $e_{4} e_{5}$ & $\ldots$ & - & - \\
\hline$\vdots$ & $\vdots$ & $\vdots$ & $\vdots$ & $\vdots$ & $\vdots$ & $\because$ & $\vdots$ & $\vdots$ \\
\hline$e_{n-1}$ & - & - & - & - & - & $\ldots$ & - & $e_{n-1} e_{n}$ \\
\hline$e_{n}$ & - & - & - & - & - & $\ldots$ & - & - \\
\hline
\end{tabular}

Tabel 2 Pengkonstruksian Graf $M\left(C_{n}\right)$ dengan Syarat Satu Simpul dan yang Lainnya Bersisian pada Sisinya

\begin{tabular}{|c|c|c|c|c|c|c|c|}
\hline & $e_{1}$ & $e_{2}$ & $e_{3}$ & $e_{4}$ & $\ldots$ & $e_{n-1}$ & $e_{n}$ \\
\hline$v_{1}$ & $v_{1} e_{1}$ & - & - & - & $\ldots$ & - & $v_{1} e_{n}$ \\
\hline$v_{2}$ & $v_{2} e_{1}$ & $v_{2} e_{2}$ & - & - & $\ldots$ & - & - \\
\hline$v_{3}$ & - & $v_{3} e_{2}$ & $v_{3} e_{3}$ & - & $\ldots$ & - & - \\
\hline$v_{4}$ & - & - & $v_{4} e_{3}$ & $v_{4} e_{4}$ & $\ldots$ & - & - \\
\hline$\vdots$ & $\vdots$ & $\vdots$ & $\vdots$ & $\vdots$ & $\because$ & $\vdots$ & $\vdots$ \\
\hline$v_{n-1}$ & - & - & - & - & $\cdots$ & $v_{n-1} e_{n-1}$ & - \\
\hline$v_{n}$ & - & - & - & - & $\ldots$ & $v_{n} e_{n-1}$ & $v_{n} e_{n}$ \\
\hline
\end{tabular}

Setelah terbentuk graf $M\left(C_{n}\right)$, dicari orde dan ukuran dari graf $M\left(C_{n}\right)$. Adapun orde dan ukuran graf $M\left(C_{n}\right)$ dituangkan dalam Observasi 6 sebagai berikut.

Observasi 6 Graf $M\left(C_{n}\right)$ memiliki orde sebesar $2 n$ dan ukuran sebesar $3 n$ untuk $n \geq 3, n \in \mathbb{Z}^{+}$. 
Bukti. Diasumsikan bahwa $U_{3}$ adalah suku pertama dan $n \geq 3$. Diketahui $\left|V\left(M\left(C_{3}\right)\right)\right|=6$, $\left|V\left(M\left(C_{4}\right)\right)\right|=8,\left|V\left(M\left(C_{5}\right)\right)\right|=10,\left|V\left(M\left(C_{6}\right)\right)\right|=12,\left|V\left(M\left(C_{7}\right)\right)\right|=14$ dan seterusnya. Akan dibuktikan bahwa $\left|V\left(M\left(C_{n}\right)\right)\right|=2 n$ dengan menggunakan rumus barisan aritmatika sebagai berikut. $U_{3}=6 ; U_{4}=8 ; U_{5}=10 ; U_{6}=12 ; U_{7}=14$, dan seterusnya. Kemudian diperoleh:

$U_{n}=a+(n-3) b=6+(n-3) 2=2 n$, sehingga $\left|V\left(M\left(C_{n}\right)\right)\right|=2 n$. Selanjutnya akan dicari ukuran dari graf $M\left(C_{n}\right)$. Diketahui $\left|E\left(M\left(C_{3}\right)\right)\right|=9, \quad\left|E\left(M\left(C_{4}\right)\right)\right|=12, \quad\left|E\left(M\left(C_{5}\right)\right)\right|=15$, $\left|E\left(M\left(C_{6}\right)\right)\right|=18,\left|E\left(M\left(C_{7}\right)\right)\right|=21$, dan seterusnya. Akan dibuktikan bahwa $\left|E\left(M\left(C_{n}\right)\right)\right|=3 n$ sebagai berikut.

$U_{3}=9 ; U_{4}=12 ; U_{5}=15 ; U_{6}=18 ; U_{7}=21$, dan seterusnya. Kemudian diperoleh:

$U_{n}=a+(n-3) b=9+(n-3) 3=3 n$, sehingga $\left|E\left(M\left(C_{n}\right)\right)\right|=3 n$. Untuk setiap $M\left(C_{n}\right)$ dengan $n \geq 3, n \in \mathbb{Z}^{+}$maka diperoleh $V\left(M\left(C_{n}\right)\right)$ dan $E\left(M\left(C_{n}\right)\right)$ yang himpunannya adalah $\{6,8,10,12, \ldots$, $2 n\}$ dan $\{9,12,15, \ldots, 3 n\}$.

Selanjutnya adalah pengkonstruksian untuk graf $M\left(\right.$ pathunion $\left.C_{5}(2)\right)$. Misalkan diberikan himpunan simpul $V\left(\right.$ path union $\left.C_{m}(2)\right)=\left\{v_{1}, v_{2}, v_{3}, \ldots, v_{m}, v_{m+1}, \ldots, v_{2 m}\right\}$ dan himpunan sisi $E$ (path union $\left.C_{m}(2)\right)=\left\{e_{1}, e_{2}, \ldots, e_{m}, e_{m+1}, \ldots, e_{2 m}, e_{m+1}\right\}$. Dua simpul adalah adjacent di $M\left(\right.$ path union $\left.C_{m}(2)\right)$ dapat dilihat pada Tabel 3 dan Tabel 4 sebagai berikut.

Tabel 3 Pengkonstruksian M(Path Union dari $\left.C_{m}(2)\right)$ dengan Syarat Keduanya adalah Sisi yang Bertetangga

\begin{tabular}{|c|c|c|c|c|c|c|c|c|c|c|c|c|}
\hline & $e_{1}$ & $e_{2}$ & $e_{3}$ & $e_{4}$ & $\ldots$ & $e_{m}$ & $e_{m+1}$ & $e_{m+2}$ & $e_{m+3}$ & $\ldots$ & $e_{2 m}$ & $e_{2 m+1}$ \\
\hline$e_{1}$ & - & $e_{1} e_{2}$ & - & - & $\ldots$ & $e_{1} e_{m}$ & - & - & - & $\ldots$ & - & $e_{1} e_{2 m+1}$ \\
\hline$e_{2}$ & - & - & $e_{2} e_{3}$ & - & $\ldots$ & - & - & - & - & $\ldots$ & - & - \\
\hline$e_{3}$ & - & - & - & $e_{3} e_{4}$ & $\ldots$ & - & - & - & - & $\ldots$ & - & - \\
\hline$\vdots$ & $\vdots$ & $\vdots$ & $\vdots$ & $\vdots$ & $\ddots$ & $\vdots$ & $\vdots$ & $\vdots$ & $\vdots$ & $\because$ & $\vdots$ & $\vdots$ \\
\hline$e_{m}$ & - & - & - & - & $\ldots$ & - & - & - & - & $\ldots$ & - & $e_{m} e_{2 m+1}$ \\
\hline$e_{m+1}$ & - & - & - & - & $\ldots$ & - & - & $e_{m+1} e_{m+2}$ & - & $\ldots$ & $e_{m+1} e_{2 m}$ & $e_{m+1} e_{2 m+1}$ \\
\hline$e_{m+2}$ & - & - & - & - & $\ldots$ & - & - & - & $e_{m+2} e_{m+3}$ & $\ldots$ & - & - \\
\hline$\vdots$ & $\vdots$ & $\vdots$ & $\vdots$ & $\vdots$ & $\because$ & $\vdots$ & $\vdots$ & $\vdots$ & $\vdots$ & $\because$ & $\vdots$ & $\vdots$ \\
\hline$e_{2 m}$ & - & - & - & - & $\ldots$ & - & - & - & - & $\ldots$ & - & $e_{2 m} e_{2 m+1}$ \\
\hline$e_{2 m+1}$ & - & - & - & - & $\ldots$ & - & - & - & - & $\ldots$ & - & - \\
\hline
\end{tabular}

Tabel 4 Pengkonstruksian M(Path Union dari $\left.C_{m}(2)\right)$ dengan Syarat Satu Simpul dan yang Lainnya Bersisian pada Sisinya

\begin{tabular}{|c|c|c|c|c|c|c|c|c|c|c|c|}
\hline & $e_{1}$ & $e_{2}$ & $e_{3}$ & $e_{4}$ & $\ldots$ & $e_{m}$ & $e_{m+1}$ & $e_{m+2}$ & $\ldots$ & $e_{2 m}$ & $e_{2 m+1}$ \\
\hline$v_{1}$ & $v_{1} e_{1}$ & - & - & - & $\ldots$ & $v_{1} e_{m}$ & - & - & $\ldots$ & - & $v_{1} e_{2 m+1}$ \\
\hline$v_{2}$ & $v_{2} e_{1}$ & $v_{2} e_{2}$ & - & - & $\ldots$ & - & - & - & $\ldots$ & - & - \\
\hline$v_{3}$ & - & $v_{3} e_{2}$ & $v_{3} e_{3}$ & - & $\ldots$ & - & - & - & $\ldots$ & - & - \\
\hline$v_{4}$ & - & - & $v_{4} e_{3}$ & $v_{4} e_{4}$ & $\ldots$ & - & - & - & $\ldots$ & - & - \\
\hline$\vdots$ & $\vdots$ & $\vdots$ & $\vdots$ & $\vdots$ & $\because$ & $\vdots$ & $\vdots$ & $\vdots$ & $\ddots$ & $\vdots$ & $\vdots$ \\
\hline$v_{m}$ & - & - & - & - & $\ldots$ & $v_{m} e_{m}$ & - & - & $\ldots$ & $v_{m+1} e_{2 n}$ & - \\
\hline$v_{n+1}$ & - & - & - & - & $\ldots$ & - & $v_{m+1} e_{m+1}$ & - & $\ldots$ & - & $v_{m+1} e_{2 m+1}$ \\
\hline$v_{m+2}$ & - & - & - & - & $\ldots$ & - & $v_{m+2} e_{m+1}$ & $v_{m+2} e_{m+2}$ & $\ldots$ & - & - \\
\hline$\vdots$ & $\vdots$ & $\vdots$ & $\vdots$ & $\vdots$ & $\because$ & $\vdots$ & $\vdots$ & $\vdots$ & $\because$ & $\vdots$ & $\vdots$ \\
\hline$v_{2 m}$ & - & - & - & - & $\ldots$ & - & - & - & $\ldots$ & $v_{2 m} e_{2 m}$ & - \\
\hline
\end{tabular}

Setelah terbentuk graf $M\left(\right.$ path union $\left.C_{5}(2)\right)$, dicari orde dan ukuran dari graf $M$ (path union $\left.C_{5}(2)\right)$. Adapun orde dan ukuran graf $M\left(\right.$ path union $\left.C_{5}(2)\right)$ dituangkan dalam Observasi 7 sebagai berikut.

Observasi 7 Graf $M$ (path union $C_{m}(2)$ memiliki orde sebesar $4 m+1$ dan ukuran sebesar $6 m+6$ untuk $m \geq 3, m \in \mathbb{Z}^{+}$.

Bukti. Diasumsikan bahwa $U_{3}$ adalah suku pertama dan $m \geq 3$. Diketahui $\mid V\left(M\left(\right.\right.$ path union $\left.\left.C_{3}(2)\right)\right)|=13| V,\left(M\left(\right.\right.$ path union $\left.\left.C_{4}(2)\right)\right)|=17| V,\left(M\left(\right.\right.$ path union $\left.\left.C_{5}(2)\right)\right) \mid=$ 21, $\mid V\left(M\left(\right.\right.$ path union $\left.\left.C_{6}(2)\right)\right)|=25| V,\left(M\left(\right.\right.$ path union $\left.\left.C_{7}(2)\right)\right) \mid=29$ dan seterusnya. Akan dibuktikan bahwa $\mid V\left(M\left(\right.\right.$ path union $\left.\left.C_{m}(2)\right)\right) \mid=4 m+1$ menggunakan rumus barisan aritmatika sebagai berikut. 
$U_{3}=13 ; U_{4}=17 ; U_{5}=21 ; U_{6}=25 ; U_{7}=29$, dan seterusnya. Kemudian diperoleh: $U_{m}=a+(m-3) b=13+(m-3) 4=4 m+1$, sehingga $\mid V\left(M\left(\right.\right.$ path union $\left.C_{m}(2)\right) \mid=4 m+1$. Selanjutnya akan dicari ukuran dari graf $\mid E\left(M\left(\right.\right.$ path union $\left.C_{m}(2)\right) \mid$. Diketahui $\mid E(M($ path union $\left.\left.C_{3}(2)\right)\right)|=24| E,\left(M\left(\right.\right.$ path union $\left.\left.C_{4}(2)\right)\right)|=30, \quad| E\left(M\left(\right.\right.$ path union $\left.\left.C_{5}(2)\right)\right)|=36| E,(M($ path union $\left.\left.C_{6}(2)\right)\right)|=42| E,\left(M\left(\right.\right.$ path union $\left.\left.C_{7}(2)\right)\right) \mid=48$ dan seterusnya. Akan dibuktikan bahwa $\mid E\left(M\left(\right.\right.$ path union $\left.\left.C_{m}(2)\right)\right) \mid=6 m+6$ sebagai berikut.

$U_{3}=24 ; U_{4}=30 ; U_{5}=36 ; U_{6}=42 ; U_{7}=48$, dan seterusnya. Kemudian diperoleh:

$U_{m}=a+(m-3) b=24+(m-3) 6=6 m+6$, sehingga $\mid E\left(M\left(\right.\right.$ path union $\left.C_{m}(2)\right) \mid=6 m+6$. Untuk setiap $M$ (path union $C_{m}(2)$ dengan $m \geq 3, m \in \mathbb{Z}^{+}$maka diperoleh $V\left(M\right.$ (path union $C_{m}(2)$ ) dan $E\left(M\left(\right.\right.$ path union $\left.C_{m}(2)\right)$ yang himpunannya adalah $\{13,17,21,25, \ldots, 4 m+1\}$ dan $\{24,30,36,42$ $, \ldots, 6 m+6\}$.

Selanjutnya adalah pengkonstruksian untuk graf $M\left(T_{n, 1}\right)$. Misalkan diberikan himpunan simpul $V\left(T_{n, 1}\right)=\left\{v_{1}, v_{2}, v_{3}, \ldots, v_{n}, v_{n+1}\right\}$ dan himpunan sisi $E\left(T_{n, 1}\right)=\left\{e_{1}, e_{2}, e_{3}, \ldots, e_{n}, e_{n+1}\right\}$. Dua simpul adalah adjacent di $M\left(T_{n, 1}\right)$ dapat dilihat pada Tabel 5 dan Tabel 6 sebagai berikut.

Tabel 5 Pengkonstruksian Graf $M\left(T_{n, 1}\right)$ pada Syarat Keduanya adalah Sisi yang Bertetangga

\begin{tabular}{|c|c|c|c|c|c|c|c|c|c|}
\hline & $e_{1}$ & $e_{2}$ & $e_{3}$ & $e_{4}$ & $e_{5}$ & $\ldots$ & $e_{n-1}$ & $e_{n}$ & $e_{n+1}$ \\
\hline$e_{1}$ & - & $e_{1} e_{2}$ & - & - & - & $\ldots$ & - & $e_{1} e_{n}$ & $e_{1} e_{n+1}$ \\
\hline$e_{2}$ & - & - & $e_{2} e_{3}$ & - & - & $\ldots$ & - & - & - \\
\hline$e_{3}$ & - & - & - & $e_{3} e_{4}$ & - & $\cdots$ & - & - & - \\
\hline$e_{4}$ & - & - & - & - & $e_{4} e_{5}$ & $\cdots$ & - & - & - \\
\hline$\vdots$ & $\vdots$ & $\vdots$ & $\vdots$ & $\vdots$ & $\vdots$ & $\because$ & $\vdots$ & $\vdots$ & $\vdots$ \\
\hline$e_{n-1}$ & - & - & - & - & - & $\cdots$ & - & $e_{n-1} e_{n}$ & - \\
\hline$e_{n}$ & - & - & - & - & - & $\ldots$ & - & - & $e_{n} e_{n+1}$ \\
\hline$e_{n+1}$ & - & - & - & - & - & $\ldots$ & - & - & - \\
\hline
\end{tabular}

Tabel 2 Pengkonstruksian Graf $M\left(T_{n, 1}\right)$ pada Syarat Satu Simpul dan Yang Lainnya Bersisian pada Sisinya

\begin{tabular}{|c|c|c|c|c|c|c|c|c|}
\hline & $e_{1}$ & $e_{2}$ & $e_{3}$ & $e_{4}$ & $\ldots$ & $e_{n-1}$ & $e_{n}$ & $e_{n+1}$ \\
\hline$v_{1}$ & $v_{1} e_{1}$ & - & - & - & $\ldots$ & - & $v_{1} e_{n}$ & $v_{1} e_{n+1}$ \\
\hline$v_{3}$ & - & $v_{3} e_{2}$ & $v_{3} e_{3}$ & - & $\ldots$ & - & - & - \\
\hline$\vdots$ & $\vdots$ & $\vdots$ & $\vdots$ & $\vdots$ & $\because$ & $\vdots$ & $\vdots$ & $\vdots$ \\
\hline$v_{n-1}$ & - & - & - & - & $\ldots$ & $v_{n-1} e_{n-1}$ & - & - \\
\hline$v_{n}$ & - & - & - & - & $\ldots$ & $v_{n} e_{n-1}$ & $v_{n} e_{n}$ & - \\
\hline
\end{tabular}

Setelah terbentuk graf $M\left(T_{n, 1}\right)$, dicari orde dan ukuran dari graf $M\left(T_{n, 1}\right)$. Adapun orde dan ukuran graf $M\left(T_{n, 1}\right)$ dituangkan dalam Observasi 8 sebagai berikut.

Observasi 8 Graf $M\left(T_{n, 1}\right)$ memiliki orde sebesar $2 n+2$ dan ukuran sebesar $3 n+4$ untuk $n \geq$ $3, n \in \mathbb{Z}^{+}$.

Bukti. Diasumsikan bahwa $U_{3}$ adalah suku pertama dan $n \geq 3$. Diketahui $\left|V\left(M\left(T_{3,1}\right)\right)\right|=8$, $\left|V\left(M\left(T_{4,1}\right)\right)\right|=10,\left|V\left(M\left(T_{5,1}\right)\right)\right|=12,\left|V\left(M\left(T_{6,1}\right)\right)\right|=14,\left|V\left(M\left(T_{7,1}\right)\right)\right|=16$ dan seterusnya. Akan dibuktikan bahwa $\left|V\left(M\left(T_{n, 1}\right)\right)\right|=2 n+2$ menggunakan rumus barisan aritmatika sebagai berikut.

$U_{3}=8 ; U_{4}=10 ; U_{5}=12 ; U_{6}=14 ; U_{7}=16$, dan seterusnya. Kemudian diperoleh:

$U_{n}=a+(n-3) b=8+(n-3) 2=2 n+2, \quad$ sehingga $\left|V\left(M\left(T_{n, 1}\right)\right)\right|=2 n+2 . \quad$ Selanjutnya adalah mencari ukuran dari graf $M\left(T_{n, 1}\right)$. Diketahui $\left|E\left(M\left(T_{3,1}\right)\right)\right|=13,\left|E\left(M\left(T_{4,1}\right)\right)\right|=16$, 
$\left|E\left(M\left(T_{5,1}\right)\right)\right|=19,\left|E\left(M\left(T_{6,1}\right)\right)\right|=22,\left|E\left(M\left(T_{7,1}\right)\right)\right|=25$, dan seterusnya. Akan dibuktikan bahwa $\left|E\left(M\left(T_{n, 1}\right)\right)\right|=3 n+4$ sebagai berikut.

$U_{3}=13 ; U_{4}=16 ; U_{5}=19 ; U_{6}=22 ; U_{7}=25$, dan seterusnya. Kemudian diperoleh:

$U_{n}=a+(n-3) b=13+(n-3) 3=3 n+4$, sehingga $\left|E\left(M\left(P_{n}\right)\right)\right|=3 n+4$. Untuk setiap $M\left(T_{n, 1}\right)$ dengan $n \geq 3, n \in \mathbb{Z}^{+}$maka diperoleh $V\left(M\left(T_{n, 1}\right)\right)$ dan $E\left(M\left(T_{n, 1}\right)\right)$ yang himpunannya adalah $\{8,10,12,14, \ldots, 2 n+2\}$ dan $\{13,16,19,22, \ldots, 3 n+4\}$.

Berikut diberikan ilustrasi dari graf middle dari beberapa graf yang dibahas.

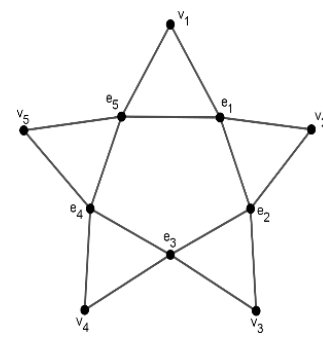

(a)

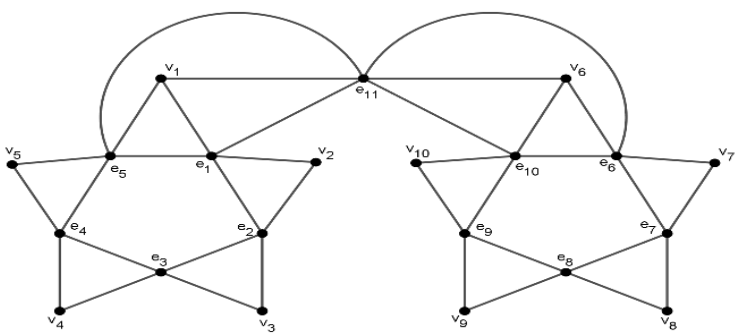

(b)

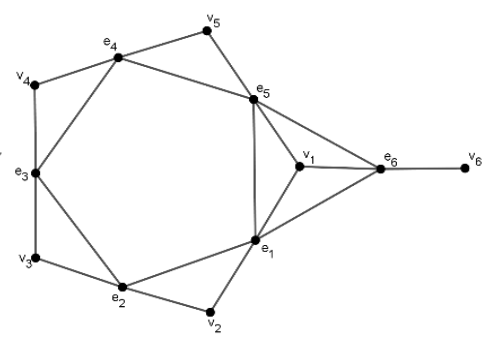

(c)

Gambar 3 (a) Graf $M\left(C_{5}\right)$, (b) Graf M(Path union $\left.C_{5}(2)\right)$, (c) Graf $M\left(T_{5,1}\right)$

\section{PELABELAN PRIME CORDIAL PADA GRAF MIDDLE DARI BEBERAPA GRAF}

Sebelum membahas pengkontruksian pelabelan prime cordial pada graf middle dari beberapa graf, terlebih dahulu diberikan definisi pelabelan prime cordial sebagai berikut.

Definisi 9 [4] Pelabelan prime cordial dari suatu graf $G$ dengan himpunan simpul $V(G)$ adalah fungsi bijektif $f: V(G) \rightarrow\{1,2,3, \ldots,|V(G)|\}$. Fungsi $f$ menginduksi fungsi $f^{*}: E(G) \rightarrow\{0,1\}$ yang didefinisikan dengan

$$
f^{*}(e=u v)=\left\{\begin{array}{l}
1 ; j i k a F P B(f(u), f(v))=1 \\
0 ; \text { lainnya }
\end{array}\right.
$$

memenuhi kondisi $\left|e_{f}(0)-e_{f}(1)\right| \leq 1$. Graf yang memuat pelabelan prime cordial disebut graf prime cordial.

Notasi $e_{f}(0)$ adalah banyaknya sisi pada $G$ yang berlabel 0 pada fungsi $f^{*}$ dan $e_{f}(1)$ adalah banyaknya sisi pada $G$ yang berlabel 1 pada fungsi $f^{*}[4]$. Berdasarkan Gambar 3, graf middle dari ke tiga graf tersebut dapat dikonstruksi menjadi graf prime cordial yang dituangkan dalam observasiobservasi berikut.

Observasi 10 Graf $M\left(C_{n}\right)$ merupakan graf prime cordial untuk $n=3$ dan $n \geq 5$, $n \in \mathbb{Z}^{+}$.

Bukti. Misalkan $v_{1}, v_{2}, \ldots, v_{n}$ dan $e_{1}, e_{2}, \ldots, e_{n}$ elemen $C_{n}$. Kemudian dikonstruksi menjadi sebuah graf middle yang himpunan simpulnya adalah $V\left(M\left(C_{n}\right)\right)=\left\{v_{1}, v_{2}, \ldots, v_{n}, e_{1}, e_{2}, \ldots, e_{n}\right\}$, diperoleh $\left|V\left(M\left(C_{n}\right)\right)\right|=2 n$ dan $\left|E\left(M\left(C_{n}\right)\right)\right|=3 n$. Didefinisikan $f: V\left(M\left(C_{n}\right)\right) \rightarrow\{1,2,3, \ldots, 2 n\}$ dan dicari bentuk pola pelabelan prime cordial dengan membuat 2 kasus yakni untuk $n$ genap dan $n$ yang ganjil.

Kasus 1: $n$ genap, $n \geq 6$

$f\left(v_{1}\right)=1$,

$f\left(v_{1+i}\right)=8+4(i-1) ; 1 \leq i \leq \frac{n}{2}-1$,

$f\left(v_{\frac{n}{2}+1}\right)=9$,

$f\left(v_{\frac{n}{2}+2}\right)=4$,
Kasus 2: $n$ ganjil, $n \geq 3$

$$
\begin{aligned}
& f\left(v_{1}\right)=1, \\
& f\left(v_{2}\right)=4, \\
& f\left(v_{2+i}\right)=10+4(i-1) ; 1 \leq i \leq\left\lfloor\frac{n}{2}\right\rfloor-1, \\
& f\left(v_{\left\lceil\frac{n}{2}\right\rceil+i}\right)=3+4(i-1) ; 1 \leq i \leq\left\lfloor\frac{n}{2}\right\rfloor,
\end{aligned}
$$


$f\left(v_{\frac{n}{2}+3}\right)=5$,

$f\left(v_{\frac{n}{2}+3+i}\right)=13+4(i-1) ; 1 \leq i \leq \frac{n}{2}-3$,

$f\left(e_{1}\right)=2$,

$f\left(e_{1+i}\right)=10+4(i-1) ; 1 \leq i \leq \frac{n}{2}-2$,

$f\left(e_{\frac{n}{2}}\right)=6$,

$f\left(e_{\frac{n}{2}+i}\right)=3+4(i-1) ; 1 \leq i \leq \frac{n}{2}$.

$$
f\left(e_{1}\right)=2,
$$$$
f\left(e_{1+i}\right)=8+4(i-1) ; 1 \leq i \leq\left\lfloor\frac{n}{2}\right\rfloor-1,
$$$$
f\left(e_{\left[\frac{n}{2}\right]}\right)=6 \text {, }
$$$$
f\left(e_{\left\lceil\frac{n}{2}\right\rceil+i}\right)=5+4(i-1) ; 1 \leq i \leq\left\lfloor\frac{n}{2}\right\rfloor .
$$

Dari Kasus 1 diperoleh himpunan yang memuat $F P B(f(u), f(v)) \neq 1$ yaitu $\left\{\left(f\left(e_{1}\right) f\left(e_{2}\right)\right)\right.$, $\left.\left(f\left(e_{2}\right) f\left(e_{3}\right)\right), \ldots,\left(f\left(e_{\frac{n}{2}}\right) f\left(e_{\frac{n}{2}+1}\right)\right)\right\} \cup\left\{\left(f\left(e_{1}\right) f\left(v_{2}\right)\right),\left(f\left(v_{2}\right) f\left(e_{2}\right)\right), \ldots,\left(f\left(v_{\frac{n}{2}+1}\right) f\left(e_{\frac{n}{2}+1}\right)\right)\right\}$ sebanyak $\frac{3 n}{2}$ dan himpunan yang memuat $\operatorname{FPB}(f(u), f(v))=1$ yaitu $\left\{\left(f\left(e_{\frac{n}{2}+1}\right) f\left(e_{\frac{n}{2}+2}\right)\right), \ldots\right.$, $\left.\left(f\left(e_{n-1}\right) f\left(e_{n}\right)\right),\left(f\left(e_{n}\right) f\left(e_{1}\right)\right)\right\} \cup\left\{\left(f\left(e_{\frac{n}{2}+1}\right) f\left(v_{\frac{n}{2}+2}\right)\right), \ldots,\left(f\left(e_{n}\right) f\left(v_{1}\right)\right),\left(f\left(v_{1}\right) f\left(e_{1}\right)\right)\right\}$ sebanyak $\frac{3 n}{2}$ sehingga $e_{f}(0)=\frac{\left|E\left(M\left(C_{n}\right)\right)\right|}{2}=\frac{3 n}{2}=e_{f}(1)$. Berdasarkan Kasus 2 diperoleh himpunan yang memuat $F P B(f(u), f(v)) \neq 1$ yaitu $\left\{\left(f\left(e_{1}\right) f\left(e_{2}\right)\right), \ldots,\left(f\left(e_{\left[\frac{n}{2}\right]}\right) f\left(e_{\left[\frac{n}{2}\right]}\right)\right)\right\} \cup\left\{\left(f\left(e_{1}\right) f\left(v_{2}\right)\right), \ldots\right.$, $\left.\left(f\left(e_{\left\lceil\frac{n}{2}\right\rceil}\right) f\left(v_{\left[\frac{n}{2}\right\rceil+1}\right)\right)\right\}$ sebanyak $\left\lfloor\frac{3 n}{2}\right\rfloor$ dan himpunan yang memuat $F P B(f(u), f(v))=1$ yaitu $\left\{\left(f\left(e_{\left\lceil\frac{n}{2}\right\rceil}\right) f\left(e_{\left\lceil\frac{n}{2}\right\rceil+1}\right)\right), \ldots,\left(f\left(e_{n}\right) f\left(e_{1}\right)\right)\right\} \cup\left\{\left(f\left(v_{\left\lceil\left\lceil\frac{n}{2}\right\rceil+1\right.}\right) f\left(e_{\left\lceil\frac{n}{2}\right\rceil+1}\right), \ldots,\left(f\left(v_{1}\right) f\left(e_{1}\right)\right)\right\}\right.$ sebanyak $\left\lceil\frac{3 n}{2}\right\rceil$ sehingga $e_{f}(0)=\left\lfloor\frac{\left|E\left(M\left(C_{n}\right)\right)\right|}{2}\right\rfloor=\left\lfloor\frac{3 n}{2}\right\rfloor=e_{f}(1)-1$. Jadi, dari kedua kasus tersebut diperoleh $\left|e_{f}(0)-e_{f}(1)\right| \leq 1$ sehingga graf $M\left(C_{n}\right)$ merupakan graf prime cordial untuk $n=3$ dan $n \geq 5$, $n \in \mathbb{Z}^{+}$.

Untuk lebih jelas mengenai graf prime cordial pada graf middle dari graf cycle dapat dilihat pada Gambar 4 sebagai berikut.

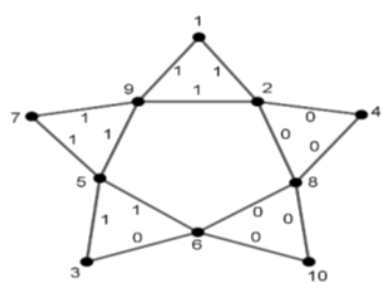

(a)

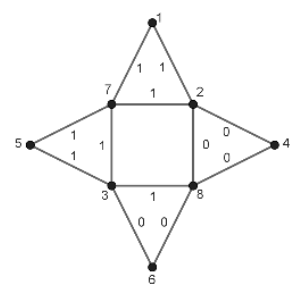

(b)

\section{Gambar 4 (a) Graf Prime Cordial M( $\left.C_{5}\right)$, (b) Bukan Graf Prime Cordial M( $\left.C_{4}\right)$}

Untuk graf $M\left(C_{4}\right)$ bukan termasuk graf prime cordial karena memiliki maksimum sisi yang berlabel 0 sebesar 5 dan minimum sisi yang berlabel 1 sebesar 7 , sehingga $\left|e_{f}(0)-e_{f}(1)\right|=|5-7|=2 \geq 1$ tidak memenuhi kondisi graf prime cordial.

Observasi 11 Graf (path union $C_{m}(2)$ ) merupakan graf prime cordial untuk $m \geq 3, m \in \mathbb{Z}^{+}$.

Bukti. Misalkan $v_{1}, v_{2}, \ldots, v_{2 m}$ dan $e_{1}, e_{2}, \ldots, e_{2 m+1}$ elemen path union $C_{m}(2)$. Kemudian dikonstruksi menjadi graf middle yang himpunan simpulnya adalah $V\left(M\left(\right.\right.$ path union $\left.\left.C_{m}(2)\right)\right)=$ $\left\{v_{1}, v_{2}, \ldots, v_{2 m}, e_{1}, e_{2}, \ldots, e_{2 m+1}\right\}$, diperoleh orde sebesar $4 m+1$ dan ukuran sebesar $6 m+6$. 
Kemudian didefinisikan $f: V\left(M\left(\right.\right.$ path union $\left.\left.C_{m}(2)\right)\right) \rightarrow\{1,2,3, \ldots, 4 m+1\}$ dan dicari bentuk pola pelabelan prime cordial sebagai berikut.

Untuk $m \geq 3, m \in \mathbb{Z}^{+}$diperoleh label sebagai berikut.

$f\left(v_{1}\right)=9$,

$$
\begin{aligned}
& f\left(e_{1}\right)=6 \\
& f\left(e_{2}\right)=8 \\
& f\left(e_{2+i}\right)=16+4(i-1) ; 1 \leq i \leq m-3 \\
& f\left(e_{m}\right)=12 \\
& f\left(e_{m+i}\right)=7+4(i-1) ; 1 \leq i \leq m-1, \\
& f\left(e_{2 m}\right)=1 \\
& f\left(e_{2 m+1}\right)=3 .
\end{aligned}
$$$$
f\left(v_{2+i}\right)=10+4(i-1) ; 1 \leq i \leq m-2 \text {, }
$$$$
f\left(v_{m+1}\right)=5 \text {, }
$$$$
f\left(v_{m+2}\right)=4 \text {, }
$$$$
f\left(v_{m+2+i}\right)=13+4(1-i) ; 1 \leq i \leq m-2 \text {, }
$$

Berdasarkan pola pelabelan tersebut diperoleh himpunan yang memuat $F P B(f(u), f(v)) \neq 1$ yaitu $\left\{\left(f\left(e_{1}\right) f\left(e_{2}\right)\right), \ldots,\left(f\left(e_{m-1}\right) f\left(e_{m}\right)\right),\left(f\left(e_{m}\right) f\left(e_{1}\right)\right),\left(f\left(e_{m}\right) f\left(e_{2 m+1}\right)\right),\left(f\left(e_{2 m+1}\right) f\left(e_{1}\right)\right)\right\} \quad \cup$ $\left\{\left(f\left(v_{1}\right) f\left(e_{1}\right)\right), \ldots,\left(f\left(e_{m}\right) f\left(v_{1}\right)\right),\left(f\left(v_{1}\right) f\left(v_{2 m+1}\right)\right)\right\}$ sebanyak $\frac{6 m+6}{2}$ dan himpunan yang memuat $F P B(f(u), f(v))=1$ yaitu $\left\{\left(f\left(e_{m+1}\right) f\left(e_{m+2}\right)\right), \ldots,\left(f\left(e_{2 m-1}\right) f\left(e_{2 m}\right)\right),\left(f\left(e_{2 m}\right) f\left(e_{2 m+1}\right)\right)\right.$, $\left.\left(f\left(e_{2 m+1}\right) f\left(e_{m+1}\right)\right)\right\} \cup\left\{\left(f\left(v_{m+1}\right) f\left(e_{m+1}\right)\right), \ldots,\left(f\left(e_{2 m}\right) f\left(v_{m+1}\right)\right),\left(f\left(v_{m+1}\right) f\left(e_{2 m+1}\right)\right)\right\}$ sebanyak $\frac{6 m+6}{2}$ sehingga $e_{f}(0)=\frac{\mid E\left(M\left(\left(\text { path union } C_{m}(2)\right)\right) \mid\right.}{2}=\frac{6 m+6}{2}=e_{f}(1)$. Jadi diperoleh $\left|e_{f}(0)-e_{f}(1)\right| \leq$ 1 sehingga graf $M\left(\right.$ path union $\left.C_{m}(2)\right)$ merupakan graf prime cordial untuk $m \geq 3, n \in \mathbb{Z}^{+}$.

Untuk lebih jelas mengenai graf prime cordial pada graf middle dari cycle dapat dilihat pada Gambar 5 sebagai berikut.

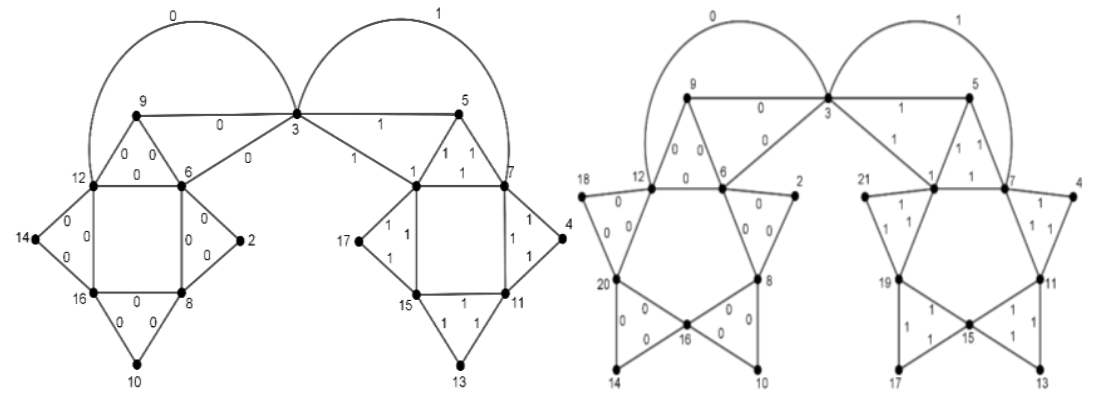

(a)

(b)

\section{Gambar 5 (a) Graf Prime Cordial M((path union $\left.\left.C_{4}(2)\right)\right)$, (b) Graf Prime Cordial $M\left(\left(\right.\right.$ path union $\left.\left.C_{5}(2)\right)\right)$}

Observasi 12 Graf $M\left(T_{n, 1}\right)$ merupakan graf prime cordial untuk $n \geq 3, n \in \mathbb{Z}^{+}$.

Bukti. Misalkan $v_{1}, v_{2}, \ldots, v_{n+1}$ dan $e_{1}, e_{2}, \ldots, e_{n+1}$ elemen $T_{n, 1}$. Kemudian dikonstruksi menjadi sebuah graf middle yang himpunan simpulnya adalah $V\left(M\left(T_{n, 1}\right)\right)=\left\{v_{1}, v_{2}, \ldots, v_{n+1}, e_{1}, e_{2}, \ldots, e_{n+1}\right\}$, diperoleh $\left|V\left(M\left(T_{n, 1}\right)\right)\right|=2 n+2$ dan $\left|E\left(M\left(T_{n, 1}\right)\right)\right|=3 n+4$. Didefinisikan $f: V\left(M\left(T_{n, 1}\right)\right) \rightarrow$ $\{1,2,3, \ldots, 2 n+2\}$ dan dicari bentuk pola pelabelan prime cordial dengan membuat 3 kasus yakni untuk $n$ genap, $n$ yang ganjil, dan khusus $n=3$.

Kasus 1: $n$ genap, $n \geq 4$

$f\left(v_{1}\right)=1$,

$f\left(v_{1+i}\right)=10+4(i-1) ; 1 \leq i \leq \frac{n}{2}-1$,

$f\left(v_{\frac{n}{2}+i}\right)=3+4(i-1) ; 1 \leq i \leq \frac{n}{2}$,
Kasus 3: $n$ ganjil, $n \geq 5$

$$
\begin{aligned}
& f\left(v_{i}\right)=8+4(i-1) ; 1 \leq i \leq\left\lfloor\frac{n}{2}\right\rfloor, \\
& f\left(v_{\left\lfloor\frac{n}{2}\right\rfloor+i}\right)=3+4(i-1) ; 1 \leq i \leq\left\lceil\frac{n}{2}\right\rfloor, \\
& f\left(v_{n+1}\right)=4,
\end{aligned}
$$




$$
\begin{array}{ll}
f\left(v_{n+1}\right)=2, & f\left(e_{i}\right)=10+4(i-1) ; 1 \leq i \leq\left\lfloor\frac{n}{2}\right\rfloor-1, \\
f\left(e_{i}\right)=8+4(i-1) ; 1 \leq i \leq \frac{n}{2}-1, & f\left(e_{\left[\frac{n}{2}\right]}\right)=6, \\
f\left(e_{\frac{n}{2}}\right)=6, & f\left(e_{\left[\frac{n}{2}\right]}\right)=9, \\
f\left(e_{\frac{n}{2}+1}\right)=9, & f\left(e_{\left[\frac{n}{2}\right]+1}\right)=5, \\
f\left(e_{\frac{n}{2}+2}\right)=5, & f\left(e_{\left[\frac{n}{2}\right]+1+i}\right)=13+4(i-1) ; 1 \leq i \leq\left\lfloor\frac{n}{2}\right\rfloor-2, \\
f\left(e_{\frac{n}{2}+2+i}\right)=13+4(i-1) ; 1 \leq i \leq \frac{n}{2}-2, & f\left(e_{n}\right)=1, \\
f\left(e_{n+i}\right)=4 . & f\left(e_{n+1}\right)=2 .
\end{array}
$$

Kasus 2: $n$ ganjil, $n=3$

$f\left(v_{1}\right)=8 ; f\left(v_{2}\right)=3 ; f\left(v_{3}\right)=7 ; f\left(v_{4}\right)=1 ; f\left(e_{1}\right)=2 ; f\left(e_{2}\right)=5 ; f\left(e_{3}\right)=6 ; f\left(e_{4}\right)=4$.

Dari Kasus 1 diperoleh himpunan yang memuat $F P B(f(u), f(v)) \neq 1$ yaitu $\left\{\left(f\left(e_{n+1}\right) f\left(e_{1}\right)\right)\right.$, $\left.\left(f\left(e_{1}\right) f\left(e_{2}\right)\right), \ldots,\left(f\left(e_{\frac{n}{2}}\right) f\left(e_{\frac{n}{2}+1}\right)\right)\right\} \cup\left\{\left(f\left(e_{1}\right) f\left(v_{2}\right)\right),\left(f\left(v_{2}\right) f\left(e_{2}\right)\right), \ldots,\left(f\left(v_{\frac{n}{2}+1}\right) f\left(e_{\frac{n}{2}+1}\right)\right)\right\}$ sebanyak $\frac{3 n+4}{2}$ dan himpunan yang memuat $\operatorname{FPB}(f(u), f(v))=1$ yaitu $\left\{\left(f\left(e_{\frac{n}{2}+1}\right) f\left(e_{\frac{n}{2}+2}\right)\right), \ldots\right.$, $\left(f\left(e_{n}\right) f\left(e_{1}\right)\right),\left(f\left(e_{n}\right) f\left(e_{n+1}\right)\right) \cup\left\{\left(f\left(e_{\frac{n}{2}+1}\right) f\left(v_{\frac{n}{2}+2}\right)\right), \ldots,\left(f\left(e_{n}\right) f\left(v_{1}\right)\right), \quad\left(f\left(v_{1}\right) f\left(e_{1}\right)\right)\right.$, $\left(f\left(v_{1}\right) f\left(e_{n+1}\right)\right)$, sebanyak $\frac{3 n+4}{2}$ sehingga diperoleh $e_{f}(0)=\frac{\left|E\left(M\left(T_{n, 1}\right)\right)\right|}{2}=\frac{3 n+4}{2}=e_{f}(1)$. Selanjutnya, berdasarkan Kasus 2 diperoleh himpunan yang memuat $F P B(f(u), f(v)) \neq 1$ yaitu $\left\{\left(f\left(e_{1}\right) f\left(e_{3}\right)\right)\right.$, $\left.\left(f\left(v_{1}\right) f\left(e_{1}\right)\right),\left(f\left(v_{1}\right) f\left(e_{3}\right)\right),\left(f\left(v_{1}\right) f\left(e_{4}\right)\right),\left(f\left(e_{4}\right) f\left(e_{1}\right)\right),\left(f\left(e_{3}\right) f\left(e_{4}\right)\right)\right\}$ sebanyak 6 dan himpunan yang memuat $F P B(f(u), f(v))=1$ yaitu $\left\{\left(f\left(e_{4}\right) f\left(v_{4}\right)\right), \quad\left(f\left(e_{1}\right) f\left(v_{2}\right)\right), \quad\left(f\left(e_{1}\right) f\left(e_{2}\right)\right)\right.$, $\left.\left(f\left(e_{2}\right) f\left(e_{3}\right)\right), \quad\left(f\left(e_{2}\right) f\left(v_{2}\right)\right) \quad\left(f\left(e_{2}\right) f\left(v_{3}\right)\right), \quad\left(f\left(v_{3}\right) f\left(e_{3}\right)\right)\right\}$ sebanyak 7, sehingga $e_{f}(0)=$ $\left\lfloor\frac{E\left(M\left(T_{n, 1}\right)\right)}{2}\right\rfloor=\left\lfloor\frac{3 n+4}{2}\right\rfloor=e_{f}(1)-1$ dan berdasarkan pada Kasus 3 diperoleh himpunan yang memuat $F P B(f(u), f(v)) \neq 1$ yaitu $\left\{\left(f\left(e_{n+1}\right) f\left(e_{1}\right)\right),\left(f\left(e_{1}\right) f\left(e_{2}\right)\right), \ldots,\left(f\left(e_{\left[\frac{n}{2}\right]}\right) f\left(e_{\left[\frac{n}{2}\right]}\right)\right)\right\} \cup\left\{\left(f\left(v_{1}\right) f\left(e_{1}\right)\right)\right.$, $\left.\left(f\left(e_{1}\right) f\left(v_{2}\right)\right), \ldots,\left(f\left(v_{\left\lceil\frac{n}{2}\right\rceil}\right) f\left(e_{\left\lceil\frac{n}{2}\right\rceil}\right)\right),\left(f\left(v_{1}\right) f\left(e_{n+1}\right)\right),\left(f\left(e_{n+1}\right) f\left(v_{n+1}\right)\right)\right\}$ sebanyak $\left\lceil\frac{3 n+4}{2}\right\rceil$ dan himpunan yang memuat $\operatorname{FPB}(f(u), f(v))=1$ yaitu $\left\{\left(f\left(e_{\left[\frac{n}{2}\right]}\right) f\left(e_{\left[\frac{n}{2}\right]+1}\right)\right), \ldots, \quad\left(f\left(e_{n}\right) f\left(e_{1}\right)\right)\right.$, $\left.\left(f\left(e_{n}\right) f\left(e_{n+1}\right)\right)\right\} \quad \cup\left\{\left(f\left(e_{\left[\frac{n}{2}\right]}\right) f\left(v_{\left[\frac{n}{2}\right\rceil+1}\right), \ldots,\left(f\left(v_{n}\right) f\left(e_{n}\right)\right),\left(f\left(e_{n}\right) f\left(v_{1}\right)\right)\right\}\right.$ sebanyak $\left\lfloor\frac{3 n+4}{2}\right\rfloor$ sehingga $e_{f}(0)=\left\lceil\frac{\left|E\left(M\left(T_{n, 1}\right)\right)\right|}{2}\right\rceil=\left\lceil\frac{3 n+4}{2}\right\rceil=e_{f}(1)+1$. Jadi, dari ketiga kasus tersebut diperoleh $\left|e_{f}(0)-e_{f}(1)\right| \leq 1$ sehingga graf $M\left(T_{n, 1}\right)$ merupakan graf prime cordial untuk $n \geq 3, n \in \mathbb{Z}^{+}$.

Untuk lebih jelas mengenai graf prime cordial pada graf middle dari graf pan dapat dilihat pada Gambar 6 sebagai berikut. 


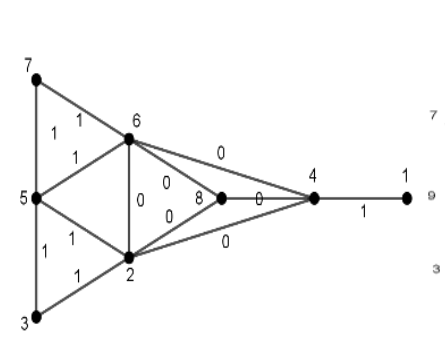

(a)

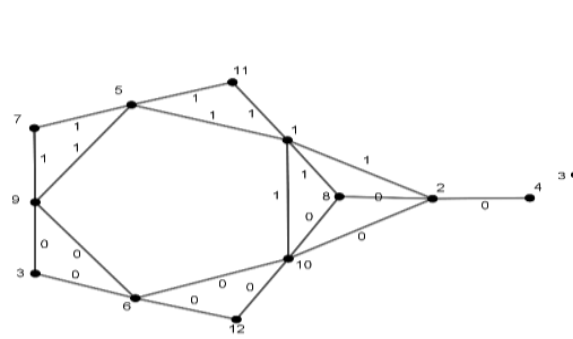

(b)

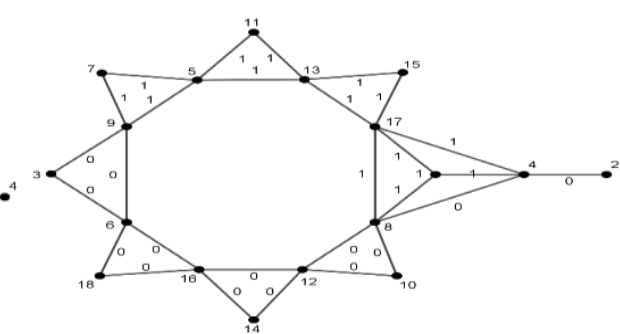

(c)

Gambar 6 (a) Graf Prime Cordial M(T,1), (b) Graf Prime Cordial M( $\left.T_{5,1}\right)$, (c) Graf Prime Cordial $M\left(T_{8,1}\right)$,

\section{KESIMPULAN}

Berdasarkan observasi penelitian yang telah dilakukan, maka dapat disimpulkan bahwa graf $M\left(C_{n}\right)$ memiliki orde sebesar $2 n$ dan ukuran sebesar $3 n$ untuk $n \geq 3, n \in \mathbb{Z}^{+}$, graf $M$ ( path unionC ${ }_{m}(2)$ ) memiliki orde sebesar $4 m+1$ dan ukuran sebesar $6 m+6$ untuk $m \geq 3, m \in \mathbb{Z}^{+}$dan graf $M\left(T_{n, 1}\right)$ memiliki orde sebesar $2 n+2$ dan ukuran sebesar $3 n+4$ untuk $n \geq 3, n \in \mathbb{Z}^{+}$. Untuk graf prime cordial diperoleh graf $M\left(C_{n}\right)$ merupakan graf prime cordial untuk $n=3$ dan $n \geq 5$, graf $M$ (path union $\left.C_{m}(2)\right)$ merupakan graf prime cordial untuk $m \geq 3$, dan graf $M\left(T_{n, 1}\right)$ merupakan graf prime cordial untuk $n \geq 3, n, m \in \mathbb{Z}^{+}$.

\section{DAFTAR PUSTAKA}

[1] Cahayani, K.P.; Soelistyo, R.H.; dan Zaki, S. Pelabelan Cordial dan Gracefull pada Arbitrary Supersubdivision Graf Path dan Star. Universitas Diponegoro. 2013.

[2] Prasanna, N.L.; Sravanthi, K.; dan Sudhakar, N. Application of Graph Labeling in Major Areas of Computer Science. IJRCCT. 2014; Vol. 3.

[3] Pranata, S.; Sudarsana, I. W.; dan Musdalifah, S. Pelabelan Prime Cordial Untuk Graf Buku dan Graf Matahari Yang Diperumum. JIMT. 2017; 14: 56-69.

[4] Vaidya, S.K. dan Shah, N.H. Prime Cordial Labeling of Some Graphs. Open Journal of Discrete Mathematics. 2012; 2: 11-16.

[5] Vaidya, S.K. dan Bantva, D.D. The L $(2,1)$ Labeling of Some Middle Graphs. Journal of Applied Computer Science \& Mathematics. 2010; 9(4):104-107.

[6] Munir, R. Matematika Diskrit Ed ke-3. Bandung: Teknik Informatika; 2010.

[7] Chartrand, G. dan Oellermann, O.R. Applied and Algorithmic Graph Theory. New York: McGraw-Hill; 1993.

[8] Chartrand, G. dan Lesniak, L. Graphs and Digraphs Third Edition. Florida: Chapman and Hall/CRC; 1996.

[9] Babujee, J.B. dan Shobana, L. Prime and Prime Cordial Labeling for Some Special Graphs. IJCMS. 2010; Vol. 5.

[10] Siddiqui, N. dan James, M. Domination and Chromatic Number of Pan and Lollipop Graph. IJTIMES. 2018; Vol. 4.

APISTINO : Jurusan Matematika FMIPA UNTAN, Pontianak apistinoapis@gmail.com

YUNDARI : Jurusan Matematika FMIPA UNTAN, Pontianak yundari@math.untan.ac.id

HELMI : Jurusan Matematika FMIPA UNTAN, Pontianak helmi132205@yahoo.co.id 